\title{
Alexandre Dumas, La Reine Margot. Drame
}

\section{Michel Arrous}

\section{(2) OpenEdition}

\section{Journals}

\section{Édition électronique}

URL : http://journals.openedition.org/studifrancesi/5389

DOI : 10.4000/studifrancesi.5389

ISSN : 2427-5856

\section{Éditeur}

Rosenberg \& Sellier

\section{Édition imprimée}

Date de publication : 1 décembre 2016

Pagination : $545-546$

ISSN : 0039-2944

\section{Référence électronique}

Michel Arrous, «Alexandre Dumas, La Reine Margot. Drame», Studi Francesi [En ligne], 180 (LX | III) |

2016, mis en ligne le 01 janvier 2017, consulté le 18 septembre 2020. URL : http://

journals.openedition.org/studifrancesi/5389; DOI : https://doi.org/10.4000/studifrancesi.5389

\section{Ce document a été généré automatiquement le 18 septembre 2020}

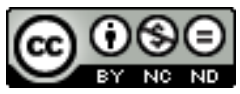

Studi Francesi è distribuita con Licenza Creative Commons Attribuzione - Non commerciale - Non opere derivate 4.0 Internazionale. 


\title{
Alexandre Dumas, La Reine Margot. Drame
}

\author{
Michel Arrous
}

\section{RÉFÉRENCE}

Alexandre Dumas, La Reine Margot. Drame, édition de Sylvain Ledda, Paris, Classiques Garnier, 2014, 448 pp.

1 La dernière édition de La Reine Margot remontant à 1865, il était nécessaire d'en proposer une nouvelle. Sylvain Ledda s'en est chargé en présentant, dans une préface précise et enlevée, à la fois historique et analytique, le «drame en cinq actes et treize tableaux» - en fait une version resserrée, mais près de neuf heures de théâtre! - de Dumas et Maquet, ce dernier étant un co-auteur dont le rôle d'adaptateur du roman est difficile à définir. La Reine Margot a fait date dans la carrière théâtrale de Dumas, mais aussi dans l'histoire du drame romantique, alors sur le déclin, car la première du 20 février 1847, pour l'ouverture du Théâtre-Historique, fut un événement tonitruant. À la fois auteur et entrepreneur, Dumas a réussi un «théâtre total», car sa fresque, ponctuée de scènes spectaculaires, fut un succès financier et l'illustration éclatante d'une rénovation du théâtre romantique.

2 Après avoir retracé les débuts du Théâtre-Historique et évoqué l'agitation médiatique qui entoura la première, S. Ledda aborde les caractéristiques dramaturgiques et scénographiques de la poétique de Dumas, avec ses invariants, déjà présents dans Henri III et sa cour, comme l'intérêt pour le $\mathrm{XVI}^{\mathrm{e}}$ siècle, le choix des moments décisifs de l'histoire nationale, et les constantes que sont la «rencontre entre une figure secondaire» - La Môle, un simple comparse dont Dumas fait un héros - et «la trajectoire des grands de ce monde»- les derniers Valois -, ainsi surtout que la mise en scène de «la confrontation entre un destin individuel et une crise collective majeure» (p.19). Sont finement étudiés la gestion des pittoresques et dangereux lieux du drame, l'usage du décor architecturé, l'élargissement de l'espace scénique (la teichoscopie pour les 
scènes violentes), le recours aux ressorts du mélodrame et surtout l'usage du tableau: «Sur fond de massacre des Protestants, le traitement de l'espace permet à la conspiration de circuler et de transpirer des murs; il rend visible la dimension occulte du pouvoir» (p. 21). La Saint-Barthélemy n'est pas représentée, mais son horreur est suggérée: «le pire se déroule hors-scène» (p. 29). Dans cette œuvre dont Gautier a dit que «c'est un roman mis en scène, une période historique dialoguée et dramatisée», on retrouve les influences du roman historique et de la tradition romantique. Abordant la question de la transposition du roman à la scène, S. Ledda relève les effets du changement générique: «les événements sont représentés sous un jour nouveau et leur sens s'en voit modifié» (p. 28). Bien qu'il soit moins proche de la vérité historique que le roman, le drame, par le resserrement temporel (parfois peu vraisemblable) et l'accélération des événements ou l'allègement d'épisodes horribles, donne de l'histoire un spectacle vivant conforme au projet du Théâtre-Historique. Dans les deux œuvres Marguerite de Valois est une figure assez éloignée de la vérité historique, mais "globalement positive», au moment même où l'on revisite sa légende jusqu'à en faire un modèle d'héroïsme ou une fascinante amoureuse (Le Rouge et le Noir, Le Pré-aux-clercs, Les Huguenots). S. Ledda fait remarquer fort justement qu'en dépit du titre Margot n'est pas le personnage principal, car Dumas a veillé à répartir les rôles de façon à ce que s'équilibrent la tragédie politique (Charles IX et Catherine de Médicis, Henri de Navarre et le duc d'Alençon) et la "comédie romanesque» (La Môle et Coconnas, Margot et Henriette). À la différence de ses prédécesseurs, Dumas n'accable pas Charles IX; en revanche, sa Catherine de Médicis, égale à la réputation que lui a faite le XIX siècle, «se situe dans la lignée des grandes héroïnes du théâtre romantique, maléfique et destructrice» (p. 32). Fidèle à l'esthétique romantique, Dumas ne conçoit pas le drame, si noir soit-il, sans une part de légèreté, voire de grotesque faisant office de «détente du suspens» (p. 39), dans la bonhomie ou le comique macabre de Coconnas, l'ironie de Henri de Navarre ou la familiarité des hommes du peuple «Dumas équilibre ainsi les registres et rend d'autant plus saillants les moments tragiques ou violents» (p. 39). Autre singularité mise en évidence dans la préface: les histoires d'amour, entre Mathilde et La Môle, et d'amitié, entre La Môle et Coconnas, sont intégrées au drame historique. Dumas a procédé à une relecture ou à une fictionnalisation de l'histoire, en concentrant le regard du public sur le spectacle d'un clan familial qui se déchire. Relecture certes discutable mais qui laisse transparaitre une claire intention politique à un an de la révolution de 1848: «En février 1847 le temps des rois et des reines est bientôt passé» (p. 43).

3 Le texte de cette édition est celui du Théâtre complet (1864). Auparavant, il avait paru chez Michel Lévy en mars 1847 et fut réédité en 1853. La pièce, «un très grand succès, mais pas un triomphe» (quatre-vingt-quatorze représentations en 1847) fut reprise en 1856, 1859, 1868 (Barbey la jugea «démodée»), 1876 et 1889. Ce succès populaire a été éclipsé par celui du roman et du film de Chéreau dont les choix esthétiques ne s'éloignent pas de la conception dumasienne de la représentation de l'histoire (voir les «Notes sur La Reine Margot de Patrice Chéreau», pp. 431-436). Figurent en fin de volume un relevé des variantes du manuscrit indiquant les passages supprimés à la représentation et pour l'édition, ainsi que quatre appendices (pp. 365-430). Dans les deux premiers on trouvera des notices sur les personnages historiques et une étude de la suppression ou du déplacement de plusieurs passages du manuscrit après la première représentation et lors de la publication (élagage tenant compte des exigences de la censure, amputation de scènes non essentielles à l'intrigue); le troisième donne les 
feuilletons de Gautier et de Janin; le quatrième deux scènes de La Reine Argot, une des trois parodies qui témoignent $d u$ succès du drame de Dumas. La très complète bibliographie, où l'on découvre une autre affaire de famille puisque Marie-Joseph Chénier se voit dépossédé de Charles IX ou l'École des rois au profit de son frère, signale, pour les études critiques et historiques, les sources possibles ou probables de Dumas et Maquet. 